\title{
STUDY OF CAROTID INTIMA MEDIA THICKNESS IN PATIENTS WITH ACUTE ISCHEMIC STROKE AND ITS CORRELATION WITH RISK FACTORS OF ISCHEMIC STROKE - A CASE CONTROL STUDY
}

Rajeev $\mathrm{H}^{1}$, Krishnappa를 Savitha $\mathrm{V}^{3}$

\section{HOW TO CITE THIS ARTICLE:}

Rajeev H, Krishnappa, Savitha V. "Study of carotid intima media thickness in patients with acute ischemic stroke and its correlation with risk factors of ischemic stroke - a case control study". Journal of Evolution of Medical and Dental Sciences 2013; Vol. 2, Issue 44, November 04; Page: 8444-8454.

ABSTRACT: Stroke is the leading cause of mortality worldwide. Carotid Intima Media Thickness (CIMT) is a marker of atherosclerosis and is also a marker for ischemic stroke. AIMS: 1) To assess the value of carotid intima media thickness at which patients with risk factors can develop acute ischemic stroke. 2) To correlate carotid intima media thickness with risk factors of acute ischemic stroke. MATERIAL \& METHODS: This study was done at KIMS Hospital, Bangalore between December 2010 to September 2012. This is a case control observational study which has a sample size of 50 cases and 50 controls. Method of collection of data was by patient evaluation which was done by taking detailed history, clinical examination and laboratory investigations through a proforma specially designed for this study. Cases were subjects who had ischemic stoke and Infarct proven by CT/MRI of brain, Controls were subjects without stroke matched to cases by age, gender and risk factors like diabetes, hypertension, smoking and dyslipidemia. Subjects in both groups underwent carotid Doppler investigation with 7.5 Mhz linear superficial array probe to determine CIMT and presence of plaques. RESULTS: Out of 50 cases, 46 had CIMT between 0.06-0.20 cm [92\%] and out of 50 controls, 45 had CIMT between 0.06-0.20 $\mathrm{cm}$ [90\%]. Most of our cases had CIMT above $0.06 \mathrm{~cm}$, so we can hypothesize that people with risk factors having CIMT above $0.06 \mathrm{~cm}$ are more prone for ischemic cerebro vascular accidents. Mean CIMT in cases with risk factors is significantly increased when compared to controls with risk factors. CONCLUSION: People with risk factors [ age $>50$ years, DM , HTN , Smoking and Dyslipidemia] having CIMT above $0.06 \mathrm{~cm}$ are more prone for ischemic CVA, so people with risk factors should undergo screening for CIMT measurement by Carotid Doppler which is non invasive and cost effective and if their CIMT is above $0.06 \mathrm{~cm}$ they should undergo early medical intervention to take care of risk factors and lifestyle modifications, so that they can be prevented from ischemic CVA in future.

KEYWORDS: Atherosclerosis, stroke, diabetes mellitus, hypertension, age, smoking, dyslipidemia, carotid intima media thickness.

\section{INTRODUCTION:}

- Stroke, both ischemic and hemorrhagic is a common and devastating disorder. Currently stroke is the leading cause of mortality worldwide and more than $80 \%$ of deaths occurring in low and middle income countries. The incidence of stroke increases with increasing age and with elderly population worldwide.

- In most of ischemic strokes, the underlying pathophysiology is atherosclerosis. The risk factors for stroke are modifiable and non-modifiable. The modifiable risk factors are mostly related to atherosclerotic burden and include diabetes, hypertension, smoking and 
hyperlipidemia. Several risk prediction scoring systems have been evolved to identify individuals with high risk.

- However, most of these scoring systems have some limitations. The carotid intima media thickness has emerged as a reliable independent marker of atherosclerosis and cerebrovascular disease. However well-defined population cut off value for CIMT is not there.

So in this study we are trying to see at what value of CIMT the individual with risk factors will be prone for stroke in our study population. An increas ed CIMT may help select patients at high risk for brain infarction and change in their lifestyle and prophylactic treatment with statins may prevent this devastating event.

METHODOLOGY: This study was done at Kempegowda Institute of Medical Sciences, Bangalore, between December 2010 to September 2012. This is a case control observational study which had a sample size of 50 cases and 50 controls.

SOURCE OF DATA: Cases were patients with ischemic stroke admitted to KIMS Hospital who fulfilled inclusion criteria and Controls were selected from inpatient and outpatient department of KIMS Hospital.

METHOD OF COLLECTION OF DATA: Method of collection of data was by patient evaluation which was done by taking detailed history, clinical examination and laboratory investigations through a proforma specially designed for this study.

\title{
CASES : $\quad$ INCLUSION CRITERIA
}

\author{
Age 40-70 years \\ Both the sexes \\ Clinical symptoms/signs suggestive of ischemic stroke \\ Infarct proven by CT/MRI of brain
}

\section{EXCLUSION CRITERIA}

Patients with valvular heart diseases

Pregnancy and postpartum stroke

Patients with past history of connective tissue disorders/vasculitis

Recurrent strokes

Patients on statin therapy for more than 1 year for any indication

CONTROLS: 50 controls from inpatient and outpatient department of KIMS HOSPITAL matched by age, gender and risk factors like diabetes, hypertension, smoking and dyslipidemia.

All patients were subjected to the following lab investigations complete hemogram, Blood urea, Serum Creatinine, RBS/FBS/PPBS, Fasting Lipid Profile, ECG, 2DECHO,CT or MRI BRAIN. Carotid atery Doppler by U/S. 
CAROTID ARTERY DOPPLER - Ultrasonographic scanning of carotid arteries was performed using higher resolution B mode colour doppler imaging and an electrical linear transducer of 7.5Mhz was used.

CIMT is anechoic zone between two echogenic lines, first echo is lumen-intima surface, second echo is caused by media-adventitia interface.

CIMT is measured at 3 levels in both the carotids and in areas free of plaques-

- Common carotid artery

- Bifurcation of Common carotid artery

- Internal carotid artery

Highest value in each carotid is taken and average of 2 measures is taken as CIMT.

After all the necessary tests, we have done the analysis of CIMT in Cases and Controls and Risk factors of Ischaemic stroke.

STATISTICAL METHODS: Descriptive statistical analysis has been carried out in the present study. Results on continuous measurements are presented on Mean \pm SD (Min-Max) and results on categorical measurements are presented in Number (\%). Significance is assessed at $5 \%$ level of significance. The following assumptions on data is made, Assumptions: 1. Dependent variables should be normally distributed, 2 . Samples drawn from the population should be random, Cases of the samples should be independent, student $t$ test (two tailed, independent) has been used to find the significance of study parameters on continuous scale between two groups Inter group analysis) on metric parameters. Leven's test for homogeneity of variance has been performed to assess the homogeneity of variance. Chi-square /Fisher exact test has been used to find the homogeneity of samples on categorical scale. ROC curve analysis to predict the CIMT as marker.

ETHICAL CLEARANCE: This study was approved by ethical committee of KIMS Bangalore.

RESULTS: Our study is a Comparative study of 50 cases and 50 controls in which we have studied the CIMT values and its correlation to the risk factors of Cerebrovascular Accident.

In age group of 40-50 years, there are 10 cases and 11 controls. In age group 51-60 years, there are 13 cases and 12 controls. In age group 61-70 years, there are 27 cases and 27 controls which corresponds to $54 \%$. In age group $40-50$ years CIMT in cases is $0.08 \pm 0.03$, in controls, it is $0.07 \pm 0.01$, In age group 51-60 years CIMT in cases is $0.11 \pm 0.04$, in controls, it is $0.074 \pm 0.01$, In age group 61-70 years, CIMT in cases is $0.13 \pm 0.021$, in controls, it is $0.07 \pm 0.02$, Mean CIMT(0.13 \pm 0.021 ) is more in age group 61-70 years, as age increases CIMT also increased in cases in our study.

In cases, $74 \%(n=37)$ are males and $26 \%(n=13)$ are females. In controls, $74 \%(n=37)$ are males and $26 \%(n=13)$ are females. In cases, Mean CIMT in males is $0.097 \pm 0.04$ and in females $0.17 \pm 0.030$. In controls, Mean CIMT in males is $0.07 \pm 0.02$ and in females $0.07 \pm 0.024$. In cases, females had increased CIMT than males in our study, but females cases are less in number in our study.

Comparison of Average CIMT in Cases and Control, In 4 cases and 5 controls CIMT is between 0.01-0.05 cm, In 28 cases and 42 controls CIMT is between 0.06-0.10 cm, In 14 cases and 3 controls CIMT is between $0.11-0.15 \mathrm{~cm}$, In 4 cases CIMT is between $0.16-0.20 \mathrm{~cm}$, So in Out of 50 
cases, 46 patients had CIMT between $0.06-0.20 \mathrm{~cm}$ (92\%) and in controls, 45 had CIMT between $0.06-0.20 \mathrm{~cm}(90 \%)$. Mean CIMT in cases is $0.121 \pm 0.015 \mathrm{~cm}$ and in controls, it is $0.07 \pm 0.02 \mathrm{~cm}$.

Comparison of Plaque in cases and control, Out of 50 cases 12 had plaques. Out of 50 controls, only 7 had plaques. Out of 50 cases, 12 had plaques and had increased CIMT $0.19 \mathrm{~cm}$, when compared to controls CIMT $0.08 \mathrm{~cm}$.

Comparison of CIMT in DM as the only risk factor in cases and controls, In cases, there are 2 patients with only DM as risk factor, in them Mean CIMT is $0.08 \mathrm{~cm}$. In controls, there are 2 patients with only DM as risk factor, in them Mean CIMT is $0.07 \mathrm{~cm}$.

Comparison of CIMT in HTN as the only risk factor in cases and control, In cases, there are 2 patients with only HTN as risk factor, in them Mean CIMT is $0.07 \mathrm{~cm}$. In controls, there are 2 patients with only HTN as risk factor, in them Mean CIMT is $0.06 \mathrm{~cm}$.

Comparison of CIMT in only Smokers in cases and controls, In cases, there are 5 patients with only smoking as risk factor, in them Mean CIMT is $0.07 \mathrm{~cm}$. In controls, there are 7 patients with only smoking as risk factor, in them Mean CIMT is $0.06 \mathrm{~cm}$.

Comparison of CIMT in Dyslipidemia as the only risk factor in cases and controls, In cases, there are 5 patients with only dyslipidemia as risk factor, in them Mean CIMT is $0.29 \pm 0.049$. In controls, there are 5 patients with only dyslipidemia as risk factor, in them Mean CIMT is $0.045 \pm 0.007$.

Comparison of CIMT in DM+HTN in cases and controls, In cases, there are 3 patients with $\mathrm{DM}+\mathrm{HTN}$ as risk factors, in them Mean CIMT is $0.14 \mathrm{~cm}$. In controls, there are 3 patients with $\mathrm{DM}+\mathrm{HTN}$ as risk factors, in them Mean CIMT is $0.06 \pm 0.08 \mathrm{~cm}$.

Comparison of CIMT in HTN+ Smokers in cases and controls, In cases, there are 4 patients with HTN +Smoking as risk factors, in them Mean CIMT is $0.13 \pm 0.06 \mathrm{~cm}$. In controls, there are 4 patients with HTN + Smoking as risk factors, in them Mean CIMT is $0.06 \mathrm{~cm}$.

Comparison of CIMT in DM + Dyslipidemia in cases and controls,In cases, there are 7 patients with DM+ Dyslipidemia as risk factors, in them Mean CIMT is $0.082 \pm 0.01 \mathrm{~cm}$. In controls, there are 7 patients with DM+ Dyslipidemia as risk factors, in them Mean CIMT is $0.067 \mathrm{~cm}$.

Comparison of CIMT in HTN + Dyslipidemia in cases and controls, In cases, there are 9 patients with HTN+ Dyslipidemia as risk factors, in them Mean CIMT is $0.11 \pm 0.02 \mathrm{~cm}$. In controls, there are 8 patients with HTN+ Dyslipidemia as risk factors, in them Mean CIMT is $0.10 \pm 0.03 \mathrm{~cm}$.

Comparison of CIMT in Smokers + Dyslipidemia in cases and controls, In cases, there are 5 patients with Smoking+ Dyslipidemia as risk factors, in them Mean CIMT is $0.07 \pm 0.02 \mathrm{~cm}$. In controls, there are 5 patients with Smoking+ Dyslipidemia as risk factors, in them Mean CIMT is $0.05 \pm 0.02 \mathrm{~cm}$.

Comparison of CIMT in DM +HTN+Smokers in cases and controls, In cases, there are 4 patients with DM + HTN +Smoking as risk factors, in them Mean CIMT is $0.075 \mathrm{~cm}$. In controls, there are 4 patients with DM + HTN +Smoking as risk factors, in them Mean CIMT is $0.06 \mathrm{~cm}$.

Comparison of CIMT in DM +HTN+ Dyslipidemia in cases and controls, In cases, there are 11 patients with DM + HTN +Dyslipidemia as risk factors, in them Mean CIMT is $0.09 \pm 0.04 \mathrm{~cm}$. In controls, there are 10 patients with DM + HTN +Dyslipidemia as risk factors, in them Mean CIMT is $0.082 \pm 0.006 \mathrm{~cm}$.

Comparison of CIMT in HTN+ Dyslipidemia +Smokers in cases and controls, In cases, there are 4 patients with HTN +Dyslipidemia+ Smoking as risk factors, in them Mean CIMT is 
$0.12 \pm 0.03 \mathrm{~cm}$. In controls, there are 3 patients with HTN +Dyslipidemia+ Smoking as risk factor, in them Mean CIMT is $0.095 \mathrm{~cm}$.

Comparison of CIMT in DM+ HTN+ Dyslipidemia +Smokers in cases and controls, In cases, there are 5 patients with DM +HTN + Dyslipidemia + Smoking as risk factors, in them Mean CIMT is $0.12 \pm 0.03 \mathrm{~cm}$. In controls, there are 5 patients with DM $+\mathrm{HTN}+$ Dyslipidemia + Smoking as risk factors, in them Mean CIMT is $0.08 \mathrm{~cm}$.

ROC curve analysis for predicting the CIMT as Marker, Receiver Operator Characteristics Curve(ROC). The diagnostic performance of a test, or the accuracy of a test to discriminate diseased cases from normal cases is evaluated using Receiver Operating Characteristic (ROC) curve analysis (Metz, 1978; Zweig \& Campbell, 1993). According to this The sensitivity and specificity of CIMT as marker in our study is $74 \%$ and $70 \%$.

DISCUSSION: In our study, we had both cases and controls in age groups of 40 - 50, 51-60 and 6170 years, mean age being 60 years and more no of patients are in age group 61-70 years [27 cases] .As the age increases, Mean CIMT in cases has increased drastically compared to controls that is Mean CIMT in cases in age group $41-50$ is $0.08 \mathrm{~cm}, 51-60$ is $0.11 \mathrm{~cm}$ and $61-70$ years is $0.13 \mathrm{~cm}$. In cases, mean CIMT is $0.121 \mathrm{~cm}$ (range $0.04-0.019 \mathrm{~cm}$ ) and in controls, mean CIMT is $0.07 \mathrm{~cm}$ (range $0.04-0.15 \mathrm{~cm}$ ). In study done by RATNAKAR SAHOO, when the differences in mean CIMT were compared among different age groups in the cases, there was significance with $\mathrm{P}<0.05$.

In our study there are 37 males and 13 females in both cases and control groups, In cases, Mean CIMT in males is $0.097 \pm 0.04 \mathrm{~cm}$ and in females is $0.17 \pm 0.03 \mathrm{~cm}$. In controls, Mean CIMT is $0.07 \pm 0.02 \mathrm{~cm}$ in both males and females. Mean CIMT is more in female cases than males as female cases are less in number in our study. Mean CIMT is significantly more in male cases when compared to male controls with $\mathrm{P}<0.0001$. In Study done by RATNAKAR SAHOO, differences in mean CIMT between males and females in cases were not significant; however the difference was significant in both the genders when compared to controls with $\mathrm{P}<0.001$.

In our study Mean CIMT in cases with risk factors is significantly increased when compared to controls with risk factors.

In our study, Carotid plaques are present in 12 cases and 7 controls. Mean CIMT in cases with plaques is $0.19 \pm 0.031 \mathrm{~cm}$ and in cases without plaques is $0.09 \pm 0.03 \mathrm{~cm}$. Mean CIMT in controls with plaques is $0.08 \pm 0.02 \mathrm{~cm}$ and in controls without plaques is $0.068 \pm 0.02 \mathrm{~cm}$. So Mean CIMT is high in cases and controls with plaques when compared to cases and controls without plaques. In study done by RATNAKAR SAHOO, Carotid plaques were present in 18 patients when compared to 7 in controls and CIMT was higher in patients with plaques $(0.095)$ when compared to patients without Plaques $(0.07 \mathrm{~cm})$.

In cases, mean CIMT is $0.121 \mathrm{~cm}$ (range $0.04-0.019 \mathrm{~cm}$ ) and in controls, mean CIMT is 0.07 $\mathrm{cm}$ (range $0.04-0.15 \mathrm{~cm}$ ). Mean CIMT is significantly more in cases when compared to controls with $\mathrm{P}-0.03$. In study done by RATNAKAR SAHOO, mean CIMT in cases was $0.0782 \mathrm{~cm}$ (range $0.05-0.15$ $\mathrm{cm}$ ) and in controls it was $0.059 \mathrm{~cm}$ (range $0.04-0.09 \mathrm{~cm}$ ) with $\mathrm{P}<0.0001$.

In our study, the sensitivity of CIMT as marker in our study is $74 \%$ and specificity is $70 \%$.

In a study done by RATNAKAR SAHOO, sensitivity was $48 \%$ and specificity was $96 \%$.

In our study, out of 50 cases, 46 had CIMT between $0.06-0.20 \mathrm{~cm}$ [92\%] and out of 50 controls, 45 had CIMT between $0.06-0.20 \mathrm{~cm}$ [90\%]. Most of our cases had CIMT above $0.06 \mathrm{~cm}$ so we 
can hypothesize that people with risk factors having CIMT above $0.06 \mathrm{~cm}$ are more prone for Ischemic cerebrovascular accidents so early intervention with anti platelets, statins, tight B.P control and diabetes control and lifestyle changes is essential in these people to avert future ischemic CVA.

CONCLUSION: People with risk factors [ like age > 50 years, DM , HTN , Smoking and Dyslipidemia] having CIMT above $0.06 \mathrm{~cm}$ are more prone for Ischemic Cerebro Vascular Accident, so people with risk factors should undergo screening for CIMT measurement by Carotid Doppler which is non invasive and cost effective and if their CIMT is above $0.06 \mathrm{~cm}$ they should undergo early medical intervention to take care of risk factors and lifestyle modifications, so that they can be prevented from ischemic CVA in future.

ACKNOWLEDGEMENTS: I wish to express my sincere and heartfelt gratitude to my Teachers and Hospital management. I am indebted to Dr. K.P. Suresh, Statistician , National Institute of Animal Nutrition and Physiology, Bengaluru and Dr. Gangaboraiah, Professor in Dept of Community Medicine for their generous help. My sincere thanks to all the patients who have participated in this study, without whose cooperation, this study would have been a dream. Above all, I thank the ALMIGHTY for showering me with His blessings and love, showing me the inspiration throughout my life.

\section{LIST OF ABBREVIATIONS USED [alphabetical order]}

$\begin{array}{ll}\text { ARIC } & \text { Atherosclerosis Risk in Communities } \\ \text { BMI } & \text { Body Mass Index } \\ \text { Ca } & \text { Calcium } \\ \text { CBF } & \text { Cerebral Blood Flow } \\ \text { CCA } & \text { Common Carotid Artery } \\ \text { CP } & \text { Cerebral Plaque } \\ \text { CHD } & \text { Coronary Heart Disease } \\ \text { CIMT } & \text { Carotid Intima Media Thickness } \\ \text { CVA } & \text { Cerebrovascular Disease } \\ \text { DM } & \text { Diabetes Mellitus } \\ \text { FBS } & \text { Fasting Blood Sugar } \\ \text { HTN } & \text { Hypertension } \\ \text { HDL } & \text { High Density Cholesterol } \\ \text { IC } & \text { Internal Capsule } \\ \text { ICA } & \text { Internal Carotid Artery } \\ \text { ICH } & \text { Intracranial Hemorrhage } \\ \text { IDL } & \text { Intermediate Density Lipoprotein } \\ \text { KIMS } & \text { Kempegowda Institute of Medical Sciences } \\ \text { LACS } & \text { Lacunar Syndrome } \\ \text { LDL } & \text { Low Density Lipoprotein } \\ \text { LI } & \text { Lacunar Infarcts }\end{array}$




$\begin{array}{ll}\text { LMN } & \text { Lower Motor Neuron } \\ \text { LOC } & \text { Loss of Consciousness } \\ \text { Lp(a) } & \text { Lipoprotein a } \\ \text { MCA } & \text { Middle Cerebral Artery } \\ \text { MI } & \text { Myocardial Infarction } \\ \text { MRI } & \text { Magnetic Resonance Imaging } \\ \text { NCEP } & \text { National Cholesterol Education Program } \\ \text { PPBS } & \text { Postprandial Blood Sugar } \\ \text { RBS } & \text { Random Blood Sugar } \\ \text { VLDL } & \text { Very Low Density Lipoprotein } \\ \text { PCA } & \text { Posterior Cerebral Artery } \\ \text { PICA } & \text { Posterior Inferior Cerebellar Artery } \\ \text { RIND } & \text { Reversible Ischemic Neurological Disease } \\ \text { SCA } & \text { Superior Cerebellar Artery } \\ \text { TACS } & \text { Total Anterior Circulation Syndrome } \\ \text { TC } & \text { Total Cholesterol } \\ \text { TIA } & \text { Transient Ischemic Attack } \\ \text { UMN } & \text { Upper Motor Neuron } \\ \text { WHO } & \text { World Health Organisation }\end{array}$

\section{BIBLIOGRAPHY:}

1. Ratnakar Sahoo, M. Vamshi Krishna, D. K. S Subrahmaniyan, T. K Dutta, S. Elangovan: Common Carotid Intima Media Thickness in Acute ischemic Stroke: A Case control Study; Neurology India(Sep-Oct 2009) vol 5/ issue 5.

2. Park K Parks Textbook of Preventive and Social Medicine: Banarsidas Bhanot publishers 19th edition 2010:280.

3. Shaper A G et al - Risk factors for stroke in middle aged British men BMJ 1991;302:1111-15.

4. Pierre-Jean Touboul, Alexis Elbaz, Cornelia Koller et al: Common Carotid Artery intima media thickness and brain infarction: case control study; Circulation 2000; 102:313-318.

5. Halano S, Experience from a multicentre stroke register: A preliminary report: Bulletin WHO 1976;54:541-43.

6. Jose Biller, Betsy B Love, Ischemic Cerebrovascular Disease, Neurology in Clinical Practice, Butterworth Heinemann $4^{\text {th }}$ edition $1197-1243$.

7. Jain S Maheshwari M C , Cerebrovascular Disease A review of Indian experience in past 35 years: Neuroepidemiology 1986:5:1-16.

8. Ralf L Sacco, Kargman S, Qiong Gu et al Race, Ethnicity and determination of intracranial atherosclerotic cerebral infarction, The Northern Manhalten Stroke Study, Stroke 1995;26:14020.

9. Pulsinelli W Pathophysiology of Acute Ischemic Stroke, Lancet 1992,339:533-36.

10. Howard G et al Cigarette smoking and progression of atherosclerosis JAMA 1998;279:11924.

11. Ewa Lindenstrom, Gudran Boysen, Jorgen Nybeo, Influence of Total Cholesterol, HDL cholesterol and triglycerides on risk of Cerebrovascular disease BMJ 1994;309. 
12. Charles Warlow, Stroke, TIA and Intracranial Venous thrombosis, Brains disease of the nervous system E D Michael Donaghy $11^{\text {th }}$ edition Oxford University Press 2001; 775-895.

13. Bradley et al Neurology in Clinical Practice $20044^{\text {th }}$ edition Vol 3 1197-1250.

14. Bryan R N Imaging of acute stroke Radiology 1990;177:615-6.

15. Braunwald, Douglas P et al- A textbook of Cardiovascular Medicine-9th edition

16. Harrison's Principles of Internal Medicine -18th edition

17. Pignoli $\mathrm{P}$, Tremoli E, Poli A et al Intimal plus medial thickness of arterial wall: a direct measurement with ultrasound imaging- Circulation 1986:74:1399-1406.

18. Temelkova- Kurkschiev T MD, Koehler C, Schaper F et al Relationship between fasting plasma glucose, atherosclerosis risk factors and CIMT in non diabetic individuals Diabetologia 1998; 41:706-712.

19. Damianu Baldassarre, Mauro Amarto, Aligohiero Bandioli et al, Carotid artery intima media thickness measured by ultrasonography in normal clinical practice correlates well with atherosclerosis risk factors. Stroke 2000;31:2426-2430.

20. V Mohan R Ravikumar et al:Intimal medial thickness of carotid artery in South Indian Diabetics and Non Diabetic subjects: The Chennai Urban Population Study: Diabetologia 2000:43:494-499.

21. M. Hollander, MD; M.L. Bots, MD, PhD; A. Iglesias del .Carotid Plaques increase the risk of Stroke and Subtypes of Cerebral Infarction in Asymptomatic Elderly - The Rotterdam Study . Circulation. 2002;105:2872-2877.

22. Yoji Nagai, MD, PhD; Kazuo Kitagawa, MD, PhD; Manabu Sakaguchi, MD. Significance of Earlier Carotid Atherosclerosis for Stroke Subtypes Stroke. 2001;32:1780-1785.

23. L.M. Cupini, MD; P. Pasqualetti, PhD; M. Diomedi, MD; F. Vernieri, MD Carotid Artery IntimaMedia Thickness and Lacunar Versus Non lacunar Infarcts Stroke. 2002;33:689-694.

24. Touboul PJ, Elbaz A, Koller C, Lucas C, Adrai V, Chedru F, Amarenco P. Common carotid artery intima-media thickness and brain infarction: the Etude du Profil Genetique de l'Infarctus Cerebral (GENIC) case-control study: the GENIC Investigators. Circulation.2000;102:313318.

25. Pierre-Jean Touboul, MD; Julien Labreuche, BS; Eric Vicaut. Carotid Intima-Media Thickness, Plaques, and Framingham Risk Score as Independent Determinants of Stroke Risk, Stroke. 2005;36:1741-1745.

26. Bonithon-Kopp C, Touboul PJ, Berr C, Leroux C, Mainard F, Courbon D, Ducimetiere P. Relation of intima-media thickness to atherosclerotic plaques in carotid arteries. The Vascular Aging (EVA) Study. Arterioscler Thromb Vasc Biol. 1996;16:310 -316.

27. Georgios Tsivgoulis, MD; Konstantinos Vemmos, MD; Christos Papamichael Common Carotid Artery Intima-Media Thickness and the Risk of Stroke Recurrence Stroke. 2006; 37:19131916.

28. Bots, Michiel l. MD, PhD; Hoes, Arno w. MD, PhD; Koudstaal. Common Carotid Intima-Media Thickness and risk of Stroke and Myocardial Infarction The Rotterdam study. Circulation. 1997;96:1432-1437.

29. Lloyd E. Chambless, I Aaron R. Folsom. Carotid Wall Thickness is Predictive of Incident Clinical Stroke- The Atherosclerosis Risk in Communities (ARIC) Study Am J Epidemiol 2000;151:478-87. 
30. Mahmoud Zureik, Pierre Ducimetie`re, Pierre-Jean Touboul. Common Carotid Intima-Media Thickness Predicts Occurrence of Carotid Atherosclerotic Plaques-Longitudinal Results From the Aging Vascular Study (EVA) Study. Arterioscler Thromb Vasc Biol. 2000;20:1622-1629.

31. Konstantinos N. Vemmos, Georgios Tsivgoulis, Konstantinos Spengos. Common Carotid Artery Intima-Media Thickness in Patients with Brain Infarction and Intracerebral Haemorrhage. Journal Of Neurology 2005:252-254.

32. G. Tsivgoulis, K. N. Vemmos, K. Spengos. Common carotid artery intima media thickness for the risk assessment of lacunar Infarction versus intracerebral hemorrhage Journal of Neurology 2005:252:1093-100.

33. Kazunari Matsumoto, Yasunori Sera. Correlation between common carotid arterial wall thickness and ischemic stroke in patients with type 2 diabetes mellitus metabolism 2002:51:244-247.

34. Damiano Baldassarre, PhD; Mauro Amato, PhD; Alighiero Bondioli.Carotid Artery IntimaMedia Thickness Measured by Ultrasonography in Normal Clinical Practice Correlates Well With Atherosclerosis Risk Factors Stroke 2000;31;2426-2430.

35. Relevance of Common Carotid Intima-Media Thickness and Carotid Plaque as Risk Factors for Ischemic Stroke in Patients with Type 2 Diabetes Mellitus AJNR Am J Neuroradiol 2007: 28:916-19.

36. Luigi Canciani, Sergio Castellani and Pierre-Jean Touboul. Carotid Intima Media Thickness and Plaques Can Predict the Occurrence of Ischemic Cerebrovascular Events. Stroke 2008;39;2470-2476.

37. Akihiko Kitamura, MD; Hiroyasu Iso, MD; Hironori Imano, MD. Carotid Intima-Media Thickness and Plaque Characteristics as a Risk Factor for Stroke in Japanese Elderly Men.Stroke. 2004;35:2788-2794.

38. Joseph F. Polak, MD, MPH; Sharina D. Person, PhD; Gina S. Wei, MD Segment- Specific Associations of Carotid Intima-Media Thickness With Cardiovascular Risk Factors The Coronary Artery Risk Development in Young Adults(CARDIA) Study. Stroke. 2010;41:9-15.

\begin{tabular}{|c|c|c|c|c|}
\hline \multirow{2}{*}{ Age in years } & \multicolumn{2}{|c|}{ Cases } & \multicolumn{2}{c|}{ Controls } \\
\cline { 2 - 5 } & No & \% & No & $\%$ \\
\hline $40-50$ & 10 & 20.0 & 11 & 22.0 \\
\hline $51-60$ & 13 & 26.0 & 12 & 24.0 \\
\hline $61-70$ & 27 & 54.0 & 27 & 54.0 \\
\hline Total & 50 & 100.0 & 50 & 100.0 \\
\hline Mean \pm SD & \multicolumn{2}{|c|}{$60.62 \pm 8.66$} & \multicolumn{2}{c|}{$60.42 \pm 8.35$} \\
\hline
\end{tabular}

Table 1: Age distribution of patients studied

Samples are age matched with $\mathrm{P}=0.907$

\begin{tabular}{|c|c|c|c|}
\hline Age in years & Cases & Controls & P value \\
\hline $40-50$ & $0.08 \pm 0.03$ & $0.07 \pm 0.01$ & 0.151 \\
\hline $51-60$ & $0.11 \pm 0.04$ & $0.074 \pm 0.01$ & $0.014^{*}$ \\
\hline $61-70$ & $0.13 \pm 0.021$ & $0.07 \pm 0.02$ & 0.105 \\
\hline \multicolumn{4}{|c|}{ Table 2: Comparison of CIMT in two } \\
groups studied according to age in years \\
\hline
\end{tabular}


ORIGINAL ARTICLE

\begin{tabular}{|c|c|c|c|c|}
\hline \multirow{2}{*}{ Gender } & \multicolumn{2}{|c|}{ Cases } & \multicolumn{2}{c|}{ Controls } \\
\cline { 2 - 5 } & No & $\%$ & No & $\%$ \\
\hline Male & 37 & 74.0 & 37 & 74.0 \\
\hline Female & 13 & 26.0 & 13 & 26.0 \\
\hline Total & 50 & 100.0 & 50 & 100.0 \\
\hline
\end{tabular}

\section{Table 3: Gender distribution of patients studied}

Samples are gender matched with $\mathrm{P}=1.000$

\begin{tabular}{|c|c|c|c|}
\hline Gender & Cases & Controls & P value \\
\hline Male & $0.097 \pm 0.04$ & $0.070 \pm 0.02$ & $<0.001^{* *}$ \\
\hline Female & $0.17 \pm 0.030$ & $0.07 \pm 0.024$ & 0.217 \\
\hline
\end{tabular}

Table 4: Comparison of CIMT in two gro ups studied according to gender

\begin{tabular}{|c|c|c|c|c|}
\hline \multirow{2}{*}{ CIMT } & \multicolumn{2}{|c|}{ Cases } & \multicolumn{2}{c|}{ Controls } \\
\cline { 2 - 5 } & No & $\%$ & No & $\%$ \\
\hline $0.01-0.05$ & 4 & 8.0 & 5 & 10.0 \\
\hline $0.06-0.10$ & 28 & 56.0 & 42 & 84.0 \\
\hline $0.11-0.15$ & 14 & 28.0 & 3 & 6.0 \\
\hline $0.16-0.20$ & 4 & 8.0 & 0 & 0.0 \\
\hline Total & 50 & 100.0 & 50 & 100.0 \\
\hline Mean \pm SD & \multicolumn{2}{|c|}{$0.121 \pm 0.015$} & \multicolumn{2}{c|}{$0.07 \pm 0.02$} \\
\hline Inference & $\begin{array}{c}\text { Mean CIMT is significantly more in Cases } \\
\text { when compared to controls with } \mathrm{P}=0.035^{*}\end{array}$ \\
& Table 5: Comparison of Average \\
CIMT in two groups studied
\end{tabular}

\begin{tabular}{|c|c|c|c|c|}
\hline \multirow{2}{*}{ Plaque } & \multicolumn{2}{|c|}{ Cases } & \multicolumn{2}{c|}{ Controls } \\
\cline { 2 - 5 } & No & $\%$ & No & $\%$ \\
\hline Absent & 38 & 76.0 & 43 & 86.0 \\
\hline Present & 12 & 24.0 & 7 & 14.0 \\
\hline Total & 50 & 100.0 & 50 & 100.0 \\
\hline Incidence & \multicolumn{2}{|c|}{$\begin{array}{r}\text { Incidence of Plaque are statistically more in cases (24.0\%) } \\
\text { when compared to Controls (14.0\%) with P=0.202 }\end{array}$} \\
\hline
\end{tabular}

Table 6: Comparison of Plaque in two groups studied

\begin{tabular}{|c|c|c|c|}
\hline Plaque & Cases & Controls & P value \\
\hline Absent & $0.098 \pm 0.03$ & $0.068 \pm 0.02$ & $<0.001^{* *}$ \\
\hline Present & $0.19 \pm 0.031$ & $0.08 \pm 0.02$ & 0.342 \\
\hline \multicolumn{4}{|c|}{ Table 7: Comparison of CIMT in two groups } \\
studied according to absence/presence of plaque
\end{tabular}




\begin{tabular}{|c|c|c|c|c|c|}
\hline CIMT & Sensitivity & Specificity & LR+ & LR- & AU ROC \\
\hline$>0.07$ & 74.00 & 70.00 & 2.47 & 0.37 & 0.743 \\
\hline \multicolumn{7}{c}{ Table 8: ROC curve analysis for } \\
predicting the CIMT as Marker
\end{tabular}

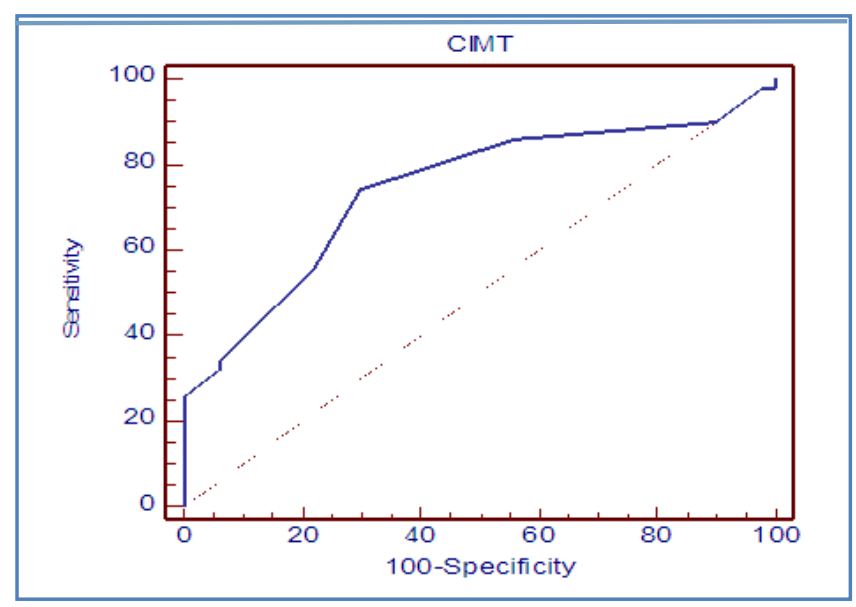

In above graph, if blue line is exactly meeting the dotted diagonal line then it indicates that the test cannot differentiate between two groups under study. Here the blue line is far away from dotted diagonal line and area covered under it is 0.743 which indicates that the test used will differentiate between two groups studied.

\section{AUTHORS:}

1. Rajeev H.

2. Krishnappa

3. Savitha V.

\section{PARTICULARS OF CONTRIBUTORS:}

1. Associate Professor, Department of General Medicine, KIMS Hospital and Research Centre, Bangalore.

2. Professor \& HOD, Department of RadioDiagnosis, KIMS Hospital and Research Centre, Bangalore.

3. Resident, Department of General Medicine, KIMS Hospital and Research Centre,

\section{NAME ADDRESS EMAIL ID OF THE CORRESPONDING AUTHOR:}

Dr. Rajeev H., Associate Professor, Departm ent of General Medicine, KIMS Hos pital and Research Centre, Bangalore. No. 1217, 3rd Main, "Anjanad ri", Chand ra Layout, Bangalore - 560040 .

Email - raajeevgowda@gmail.com

Date of Submission: 14/10/2013.

Date of Peer Review: 15/10/2013.

Date of Acceptance: 24/10/2013.

Date of Publishing: 29/10/2013 